\title{
Calcium in the heart: when it's good, it's very very good, but when it's bad, it's horrid
}

\author{
H.L. Roderick* $\dagger^{1}$, D.R. Higazi†, I. Smyrnias†, C. Fearnley†, D. Harzheim† and M.D. Bootman† \\ "Department of Pharmacology, University of Cambridge, Cambridge CB2 1PD, U.K., and †Laboratory of Molecular Signalling, Babraham Institute, Babraham \\ Research Campus, Babraham, Cambridge CB22 3AT, U.K.
}

\begin{abstract}
$\mathrm{Ca}^{2+}$ increases in the heart control both contraction and transcription. To accommodate a short-term increased cardiovascular demand, neurohormonal modulators acting on the cardiac pacemaker and individual myocytes induce an increase in frequency and magnitude of myocyte contraction respectively. Prolonged, enhanced function results in hypertrophic growth of the heart, which is initially also associated with greater $\mathrm{Ca}^{2+}$ signals and cardiac contraction. As a result of disease, however, hypertrophy progresses to a decompensated state and $\mathrm{Ca}^{2+}$ signalling capacity and cardiac output are reduced. Here, the role that $\mathrm{Ca}^{2+}$ plays in the induction of hypertrophy as well as the impact that cardiac hypertrophy and failure has on $\mathrm{Ca}^{2+}$ fluxes will be discussed.
\end{abstract}

\section{Introduction}

The co-ordinated and efficient contraction of the four chambers of the heart is essential to ensure blood supply to the body. Moreover, it is equally critical for the heart to be able to modify its output to accommodate the changing needs of the organism from states of rest to activity. It is therefore not surprising that any factors that contribute to a loss of rhythm or contractility give rise to pathological consequences. Indeed, heart disease is a significant cause of mortality, being responsible, in 2004, for 137700 deaths in the U.K., equating to $24 \%$ of all deaths [1]. These statistics surpass the 33000 deaths a year from lung cancer, 16000 deaths from colorectal cancer and 13000 deaths from breast cancer. Decompensated cardiac hypertrophy is the most important risk factor for heart failure in humans [2]. Cardiac hypertrophy is defined by an increase in the muscle mass of the heart due to cellular enlargement without any proliferation (Figure 1) [3]. Under physiological conditions that involve a requirement for increased cardiac output, such as those experienced by performance athletes and during pregnancy, hypertrophy is an adaptive response (also known as compensated hypertrophy) [3,4]. Under pathological conditions, such as hypertension, viral infection or due to mutations in genes encoding sarcomeric proteins, hypertrophy is a maladaptive response and progresses to dilated cardiomyopathy with associated fibrosis, arrhythmias and sudden death (also known as decompensated hypertrophy) $[3,4]$.

Key words: calcium flux, cardiac failure, cardiac myocyte, contraction, decompensated hypertrophy, heart disease.

Abbreviations used: ANF, atrial natriuretic factor; CaM, calmodulin; CaMKII, $\mathrm{Ca}^{2+} / \mathrm{CaM}$ dependent protein kinase II; CAMTA2, CaM-binding transcription activator 2; DAG, diacylglycerol; $E R$, endoplasmic reticulum; $E T$, endothelin; $H D A C$, histone deacetylase; $\operatorname{InS} P_{3} R$, Ins $(1,4,5) P_{3}$ receptor; MAPK, mitogen-activated protein kinase; NFAT, nuclear factor of activated Tcells; PKB, protein kinase B; PKC, protein kinase C; RyR, ryanodine receptor; SERCA, sarcoplasmic/endoplasmic-reticulum Ca2+-ATPase; SR, sarcoplasmic reticulum; TRPC, canonical transient receptor potential.

${ }^{1}$ To whom correspondence should be addressed (email Llewelyn.roderick@bbsrc.ac.uk).
To understand the molecular mechanisms that control cardiac hypertrophy and to discover targets for pharmacological intervention, research has focused on identifying and characterizing the signalling pathways and neurohumoral factors that contribute to cellular remodelling [4-7]. This research has uncovered that hypertrophic gene transcription is induced downstream of a web of multiple interdependent signalling pathways including those regulated by MAPK (mitogenactivated protein kinase) [7,8], PI3K (phosphoinositide 3kinase) $[9,10], \mathrm{PKC}$ (protein kinase C) $[11,12]$ and $\mathrm{Ca}^{2+}[6,13-$ 15] (Figure 2). These pathways are engaged following the activation of diverse classes of cell-surface receptors present in cardiac mycoytes, including (i) $\mathrm{G}_{\mathrm{q}}$-coupled receptors such as that liganded by the vasoactive peptide ET-1 (endothelin1) $[16,17]$, (ii) tyrosine kinase-like receptors, such as those activated by IGF (insulin-like growth factor) [18], and (iii) $G_{s}$-coupled receptors such as the $\beta$-adrenergic receptor, which plays such a profound role in cardiac biology $[19,20]$. Moreover, mechanical stretch and increased/modified $\mathrm{Ca}^{2+}$ cycling itself also activate the signalling pathways necessary for hypertrophic remodelling [21,22].

\section{$\mathrm{Ca}^{2+}$ signalling to hypertrophy}

As well as being directly responsible for stimulating myocyte contraction, $\mathrm{Ca}^{2+}$ also plays a key role in regulating the expression of hypertrophy-associated genes $[6,23]$. To acutely respond to greater cardiovascular demand, cardiac output is enhanced through increased $\mathrm{Ca}^{2+}$ fluxes. Longer-term requirements for greater cardiac output are brought about through hypertrophic growth. It is not therefore surprising that increased $\mathrm{Ca}^{2+}$ cycling would also be considered a trigger for the induction of hypertrophy; more work, more $\mathrm{Ca}^{2+}$, more gene transcription, more heart. The reports that hypertrophy can be induced by simply enhancing $\mathrm{Ca}^{2+}$ fluxes, via electrical 'pacing' in both cellular and animal 
Figure 1| ET-1-induced hypertrophy in neonatal rat myocytes Spontaneously beating primary cultures of rat neonatal cardiac myocytes exhibit hypertrophic growth following treatment with ET-1 (100 nM) for $24 \mathrm{~h}$. ET-1-treated myocytes have a greater surface area and sarcomeric organization as revealed by staining for $\alpha$-actinin (green). ET-1-stimulated myocytes also express ANF, which is manifest as a perinuclear ring of immunoreactivity (red). ANF is a robust indicator of hypertrophy [57]. DAPI (4',6-diamidino-2-phenylindole)-stained nuclei are indicated in blue. The white scale bar represents $20 \mu \mathrm{m}$.

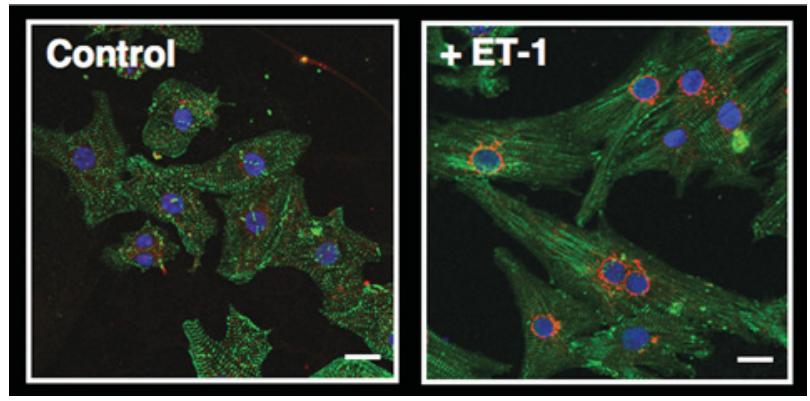

models, support this concept $[21,24]$. Moreover, the acute enhancement of $\mathrm{Ca}^{2+}$ cycling experienced by myocytes during periods of increased workload or under stress is induced by the same neurohumoral factors, such as adrenalin and ET-1, that also induce hypertrophy when chronically applied $[15,25]$. The direct role of $\mathrm{Ca}^{2+}$ for the induction of hypertrophy is also suggested by evidence obtained using transgenic models. For example, transgenic overexpression of the archetypal cellular $\mathrm{Ca}^{2+}$ sensor, $\mathrm{CaM}$ (calmodulin), induces hypertrophy [26]. It is clear that $\mathrm{Ca}^{2+}$-activated $\mathrm{CaM}$ has major signalling targets involved in the stimulation of hypertrophic gene transcription: the $\mathrm{Ca}^{2+} / \mathrm{CaM}$-activated serine/threonine phosphatase, calcineurin [also known as PP2B (protein phosphatase 2B)] [23], CAMTA2 (CaMbinding transcription activator 2) [27] and the delta isoform of CaMKII ( $\mathrm{Ca}^{2+} / \mathrm{CaM}$-dependent protein kinase II) [23]. During the induction of hypertrophy, activated calcineurin dephosphorylates NFAT3 (nuclear factor of activated T-cells 3 ), leading to its nuclear translocation and induction of target genes bearing NFAT-binding sequences in their promoters. The role of this linear pathway in cardiac myocytes was elegantly delineated by a series of publications from the Molkentin and Olsen laboratories, which showed that hypertrophy could be induced by transgenic expression of a mutated constitutively active calcineurin or of an activated form of NFAT [28]. CaMKII signalling is linked to regulation of hypertrophic gene transcription through inducing the phosphorylation of HDACs (histone deacetylases) in the nucleus, resulting in their nuclear export and removal of their inhibitory effect on gene transcription [29]. This pathway was unravelled using transgenic expression of CaMK inhibitor peptides in the nucleus and non-phosphorylatable forms of HDAC together with the use of knockout strategies [30,31]. Moreover, in response to prohypertrophic signals, HDACs are observed to translocate out of the nucleus [32]. CAMTA2
Figure 2 Signalling to cardiac hypertrophy

The Figure shows the intracellular pathways that are activated downstream of diverse prohypertrophic factors. Many of these stimuli activate increases in both $\mathrm{Ca}^{2+}$ cycling and other cellular signal-transduction cascades such as those mediated by PKC, MAPK and PKB (protein kinase $B$ ). Certain stimuli also induce increases in intracellular Ins $P_{3}$, which subsequently promotes $\mathrm{Ca}^{2+}$ release through Ins $P_{3}$ Rs that are located under the plasmalemma adjacent to RyRs or around the nucleus. $\mathrm{Ca}^{2+}$ release through the plasmalemmal Ins $P_{3}$ Rs may contribute to their inotropic function by sensitizing RyRs located there whereas $\mathrm{Ca}^{2+}$ release through nuclear Ins $P_{3} R s$ may play a role in regulating hypertrophic gene transcription. Whether these nuclear Ins $P_{3} R s$ release $\mathrm{Ca}^{2+}$ directly into the nucleus or into the adjacent cytosol is not clear. Hypertrophic gene transcription is activated downstream of MAPK, PKC and PKB signalling pathways (purple arrow). Gene transcription is also induced by changes in $\mathrm{Ca}^{2+}$ in the cytosol (orange arrow) or increases in $\mathrm{Ca}^{2+}$ in the nucleus (green arrow), where it is sensed by appropriately localized $\mathrm{Ca}^{2+}$ sensors/transcriptional activators/ co-activators. Hypertrophic remodelling is associated with increased cardiac muscle mass as well as an increase in $\mathrm{Ca}^{2+}$ signalling capacity (black dashed arrow). During heart failure, $\mathrm{Ca}^{2+}$ signalling capacity may be decreased (grey dashed arrow). VOCs, voltage-operated channels.

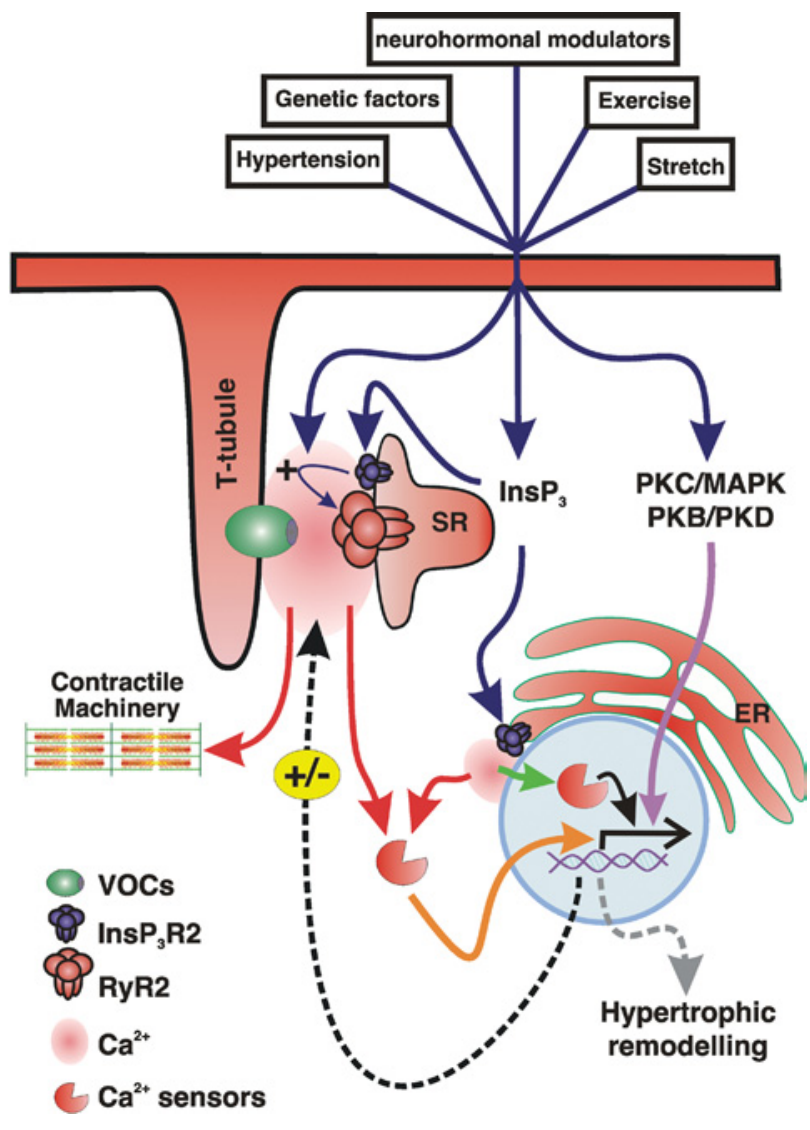

is the most recently described $\mathrm{Ca}^{2+}$-regulator of hypertrophic gene transcription [27]. It elicits its effect by acting as a coactivator of transcription factors involved in hypertrophic gene transcription. In non-stimulated cells, it remains inactive through interaction with HDACs [27]. HDACs are also 
sensitive to regulation by $\mathrm{PKC}$, providing a further $\mathrm{Ca}^{2+}$ link to DNA modification [33].

\section{Encoding specificity in $\mathrm{Ca}^{2+}$ signals}

Despite the many observations that suggest the sufficiency of enhanced $\mathrm{Ca}^{2+}$ cycling for hypertrophic remodelling, it is not clear how this signalling role of $\mathrm{Ca}^{2+}$ can be encoded above the noise of the bulk changes in $\mathrm{Ca}^{2+}$ that occur in the myocyte during every heart beat. Indeed, since these CaMregulated pathways detect changes in intracellular $\mathrm{Ca}^{2+}$ in the submicromolar range, it would be predicted that they would be activated by every $\mathrm{Ca}^{2+}$ transient during every heart beat, and, moreover, their activity would be further increased by inotropy. This ' $\mathrm{Ca}^{2+}$ only' model for the induction of hypertrophy would, however, not be advantageous for the myocyte; the array of phenotypic changes associated with hypertrophy, which include re-expression of foetally expressed genes such as ANF (atrial natriuretic factor; Figure 1), would be induced at the functional and energetic expense of the myocyte without benefit. How specificity could be imposed upon the $\mathrm{Ca}^{2+}$ signal is therefore not clear. At the most basic level, a mechanism would involve the simple integration of either an increase in the frequency and/or amplitude of the action potential-induced $\mathrm{Ca}^{2+}$ transient by the transcription machinery [34]. This would be determined by the equilibrium between the rate of activation and inactivation of the $\mathrm{Ca}^{2+}$ sensor as well as the rates of activation and inactivation of its target. For example, calcineurin responds to repetitive, low-amplitude $\mathrm{Ca}^{2+}$ transients, whereas CaMKII is activated preferentially by $\mathrm{Ca}^{2+}$ spikes that are transient and of high amplitude $[35,36]$. The equilibrium could also be shifted in favour of the activated prohypertrophic state by an increase in the diastolic $\mathrm{Ca}^{2+}$ level. This could occur through decreased $\mathrm{Ca}^{2+}$ clearance mechanisms or enhanced activation of $\mathrm{Ca}^{2+}$-release channels on the SR (sarcoplasmic reticulum). The induction of hypertrophy by overexpression of canonical members of the TRP channels (TRPCs) is also suggestive of a role of diastolic $\mathrm{Ca}^{2+}$ in hypertrophic signalling [37].

A more attractive proposal is that the subcellular location of the $\mathrm{Ca}^{2+}$ signal responsible for the induction of gene transcription is different from that which stimulates contraction. Indeed, elegant work from the Bers laboratory has shown that a $\mathrm{Ca}^{2+}$ signal generated in a microdomain around the nucleus can promote the activation of a hypertrophyassociated gene reporter construct [32]. Moreover, nuclear localized Ins $P_{3} \mathrm{R}\left[\operatorname{Ins}(1,4,5) P_{3}\right.$ receptor $] \mathrm{Ca}^{2+}$ release channels were shown to be involved in causing the depletion of the nuclear $\mathrm{Ca}^{2+}$ store, which then promoted the nuclear export of HDAC (Figure 2). This situation is analogous to that observed in skeletal muscle, where $\mathrm{Ca}^{2+}$ is released from nuclear localized Ins $P_{3}$ Rs directly into the nucleoplasm, resulting in phosphorylation of the CREB (cAMP-responseelement-binding protein) transcription factor [38]. Whether $\mathrm{Ca}^{2+}$ is released into the nucleoplasm directly or reaches there via release into the cytosol adjacent to the nucleus in cardiac myocytes remains to be determined. A further point of debate is whether this nuclear $\mathrm{Ca}^{2+}$ store is distinct from the SR. Although fluorescence recovery after photobleaching experiments indicate that it is contiguous with the SR [39], the requirement of the ER (endoplasmic reticulum) $\mathrm{Ca}^{2+}$ binding protein calreticulin for cardiac development suggests that the ER has a specialized role in the cardiac myocyte [40]. The induction of hypertrophy as a result of enhancement of store-operated $\mathrm{Ca}^{2+}$ entry by expression of TRPC family members also supports a distinct signalling role for the ER in the cardiac myocyte [37].

This idea that $\mathrm{Ca}^{2+}$ is sufficient for hypertrophic remodelling may, however, represent an over simplification of signalling in the cardiac myocyte. The phospholambanknockout mouse, for example, exhibits a constitutive inotropic state yet no hypertrophy, suggesting that other signals are required for the induction of hypertrophic remodelling [41]. Lessons gained over the past decade have indicated that signalling pathways are interdependent and co-regulated and are not generally simple linear pathways that link a receptor to its target. This butterfly effect therefore needs careful consideration. It is possible that evidence gained using transgenic overexpression approaches, although valuable, demonstrates only the possible functions of proteins in the hypertrophic response. It is plausible that they have been effective simply due to the ability of the overexpressed protein concerned to overcome numerous regulatory checkpoints in the cardiac myocyte signalling web. The presence of multiple regulatory sequences in the promoters of genes involved in the hypertrophic response suggests that this is the case.

Based on this concept, it is likely that hypertrophic gene transcription acts as a coincidence detector of many signalling inputs acting to continually assess both the cellular environment and activity. The signalling outputs of ET in the cardiac myocyte demonstrate this hypothesis. ET-1 is a vasoactive peptide that is found at elevated levels in the circulation of heart failure patients. Moreover, it is a potent prohypertrophic agonist. In cardiac muscle strips, ET-1 also has chronotropic, inotropic and arrhythmogenic effects. Myocytes express two receptors for ET-1, the $\mathrm{ET}_{\mathrm{A}} \mathrm{R}$ and the $\mathrm{ET}_{\mathrm{B}} \mathrm{R}$ [42]. The $\mathrm{ET}_{\mathrm{A}} \mathrm{R}$ is a $\mathrm{G}_{\mathrm{q}}$-coupled receptor, which following activation stimulates phospholipase $\mathrm{C}$ to cleave $\operatorname{PtdIns}(4,5) P_{2}$ into $\operatorname{Ins}(1,4,5) P_{3}$ and DAG (diacylglycerol) [43]. Ins $P_{3}$ has recently been shown to have profound effects on $\mathrm{Ca}^{2+}$ handling in the cardiac myocyte; it causes inotropy and arrhythmogenic $\mathrm{Ca}^{2+}$ release events [25]. This effect is a little surprising since $\operatorname{Ins} P_{3}$ Rs are expressed at a level almost two orders of magnitude lower than RyRs (ryanodine receptors), which are responsible for the large $\mathrm{Ca}^{2+}$ fluxes that induce myocyte contraction. Due to their special localizations around the nucleus and under the plasmalemma, as well as their ability to respond to stimuli other than $\mathrm{Ca}^{2+}$, they may however be uniquely poised to enhance the myocyte's ability to respond and adapt to its environment $[25,32]$ (Figure 2). DAG also has important functions in the myocyte. Its immediate target is PKC, which has possible signalling functions in regulating $\mathrm{Ca}^{2+}$ homoeostasis as well 
as ischaemia/reperfusion injury and inducing hypertrophy $[12,44]$. This prohypertrophic effect of PKC has received much attention and has been shown using both transgenic and pharmacological approaches to be in part via its activation of the MAPK cascade $[7,45]$.

Taken together, it is clear that signalling pathways that converge to induce hypertrophy are complex and require careful dissection. Due to the requirement for multiple inputs for the induction of hypertrophy, it is likely that disruption of any one of these pathways has a profound effect. Indeed, numerous gain- and loss-of-function animal models for signalling proteins have a profound effect on cardiac growth.

\section{Impact of hypertrophy and heart failure on $\mathrm{Ca}^{2+}$ cycling in the cardiac myocyte}

Through tipping the finely poised balance in myocyte signalling, subtle changes in $\mathrm{Ca}^{2+}$ cycling observed during physiology/pathophysiology may induce hypertrophy. However, hypertrophic growth, either compensated or decompensated, impacts on $\mathrm{Ca}^{2+}$ homoeostasis and EC (excitation-contraction) coupling. In addition to increases in cell size, adaptive hypertrophy is characterized by increased $\mathrm{Ca}^{2+}$-signalling capacity. In this way, cardiac output is maximized. A recurrent theme in studies that describe the role of $\mathrm{Ca}^{2+}$ cycling in hypertrophied myocytes is that the amplitude of each depolarization-induced $\mathrm{Ca}^{2+}$ signal is increased and its rate of recovery increased [15]. This modification of the $\mathrm{Ca}^{2+}$ signal is brought about by changes in the expression and/or activity of $\mathrm{Ca}^{2+}$ handling proteins, resulting in increased SR store loading as a result of an increase in its $\mathrm{Ca}^{2+}$-sequestration capacity, decreased $\mathrm{Na}^{+} / \mathrm{Ca}^{2+}$ exchanger activity as well as an increase in the duration of the action potential $[14,15,46]$. As the heart progresses to failure, however, its $\mathrm{Ca}^{2+}$-signalling capacity is decreased, with $\mathrm{Ca}^{2+}$ release from the SR being of a lower magnitude and being less co-ordinated [47]. A significant contributor to this phenotype is a change in the ratio of the SERCA (sarcoplasmic/endoplasmic-reticulum $\mathrm{Ca}^{2+}$-ATPase) pump to its negative regulator phospholamban, which changes in favour of phospholamban, resulting in less pump activity and lower SR Ca ${ }^{2+}$ storage [48]. The $\mathrm{Ca}^{2+}$ available for the pump is also sometimes decreased as a result of increased activity of the $\mathrm{Na}^{+} / \mathrm{Ca}^{2+}$-exchanger [49]. The SR is also depleted as a result of an increased leak through the RyR, which is brought about through the positive effect of phosphorylation and possible interaction with the immunophillin ligand FKBP12.6 (12.6 kDa FK506-binding protein) upon RyR activity $[47,50]$. Whether these changes in $\mathrm{Ca}^{2+}$ homoeostasis are a cause or consequence of disease, as well as whether they play a continued signalling role in the maintenance of the hypertrophic state, remains a matter of debate. Depending on the model being studied, both scenarios may be important. For example, recapitulation of certain $\mathrm{Ca}^{2+}$ cycling defects by overexpression of mutated $\mathrm{Ca}^{2+}$-handling proteins (such as calsequestrin), by themselves are sufficient to induce hypertrophy [51,52]. Interestingly, certain forms of heart failure can be rescued by enhancing $\mathrm{Ca}^{2+}$ signalling, for example by phospholamban deletion [48]. Furthermore, increases in $\mathrm{Ca}^{2+}$ transients are observed at early stages in the progression to hypertrophy [15]. The possibility that hypertrophy can itself cause changes in $\mathrm{Ca}^{2+}$ signals is derived from transgenic models in which hypertrophy is induced by overexpression of proteins not directly involved in $\mathrm{Ca}^{2+}$ homoeostasis. For example, myocytes isolated from mice transgenically overexpressing calcineurin also have altered $\mathrm{Ca}^{2+}$-handling characteristics. In these animals, $\mathrm{Ca}^{2+}$ sequestration into the $\mathrm{SR}$ is increased through an upregulation of SERCA expression and a decrease in phospholamban, both characteristic of hypertrophied myocytes [53]. Paradoxically, this enhanced $\mathrm{Ca}^{2+}$ signalling and associated contractility persist in individual myocytes isolated from failing hearts that actually exhibit decreased contractile properties. This discrepancy between contractility of individual myocytes and the intact heart is proposed to be due to increased fibrosis and decreased connexin-mediated connectivity between individual myocytes. These studies indicate that calcineurin signalling contributes to a positivefeedback loop that promotes the enhanced signalling capacity required for greater cardiac output as well as myocyte hypertrophy and further calcineurin activation.

These results suggest that it is likely that hypertrophy induced by genetic factors progresses differently from that induced by conditions of physiological stress (pressure overload or hormones); the requirement for an initiating $\mathrm{Ca}^{2+}$ signal is lost but the enhanced $\mathrm{Ca}^{2+}$ signals required to improve function are maintained. This enhanced $\mathrm{Ca}^{2+}$ signalling, however, has a negative effect on cell viability resulting in apoptosis. Myocytes lost through this process are replaced with fibroblasts, resulting in fibrosis of the heart and decreased contractility and conductivity as observed in the constitutively active calcineurin-overexpressing mouse [53]. In the case of hypertrophy induced by mechanical or hormonal stimuli, unlike that induced by genetic factors, an increase in $\mathrm{Ca}^{2+}$ cycling may initiate hypertrophic remodelling but as it progresses to heart failure, $\mathrm{Ca}^{2+}$ cycling is decreased $[15,47]$. The time point at which the state of the $\mathrm{Ca}^{2+}$ signalosome is assessed after the induction of hypertrophy is critical.

There is no doubt that $\mathrm{Ca}^{2+}$ homoeostasis is severely affected in heart failure models. In addition to changes in $\mathrm{Ca}^{2+}$-handling protein expression and their effects on $\mathrm{Ca}^{2+}$ transients, the $\mathrm{Ca}^{2+}$ signal and its relationship with contraction are significantly affected by ultrastructural alterations observed during heart failure. At this failing stage, the t-tubular network in ventricular myocytes atrophies, resulting in a decrease in the efficiency of coupling between the action potential and $\mathrm{Ca}^{2+}$ release [54]. It has been proposed that as well as an increase in distance between Ltype VOCCs (voltage-operated $\mathrm{Ca}^{2+}$ channels) and RyRs, which decreases the probability of successful CICR $\left(\mathrm{Ca}^{2+}\right.$ induced $\mathrm{Ca}^{2+}$ release), due to t-tubule loss, some RyRs are orphaned and no longer have an L-type channel partner [55]. These findings have recently been extended to the adaptive 
hypertrophy model, where, although there are no orphaned RyRs, the distance between the L-type channel and the RyR is increased. Thus there is a lower probability of the small amount of $\mathrm{Ca}^{2+}$ entering through the L-type channels stimulating $\mathrm{Ca}^{2+}$ release through the RyR (decreased gain) [56].

\section{Conclusions}

It is established that $\mathrm{Ca}^{2+}$ signals encode multiple levels of information. The cardiac myocyte, in terms of how it responds both acutely and in the long term to its environment, is an ultimate model of how the amplitude, timing and localization of a $\mathrm{Ca}^{2+}$ signal can be used to specifically control cellular output and cell fate. Research to understand the interplay between these different $\mathrm{Ca}^{2+}$ codes and other cellular signalling pathways and how they synergize to ultimately determine cell fate will remain a focus of future investigations.

\section{References}

1 Allender, S., Peto, V., Scarborough, P., Boxer, A. and Raynor, M. (2006) Coronary Heart Disease Statistics, British Heart Foundation, London

2 Benjamin, E.J. and Levy, D. (1999) Am. J. Med. Sci. 317, 168-175

3 Lorell, B.H. and Carabello, B.A. (2000) Circulation 102, 470-479

4 Dorn, II, G.W. and Force, T. (2005) J. Clin. Invest. 115, 527-537

5 Heineke, J. and Molkentin, J.D. (2006) Nat. Rev. Mol. Cell Biol. 7 , 589-600

6 Frey, N., McKinsey, T.A. and Olson, E.N. (2000) Nat. Med. 6, 1221-1227

7 Clerk, A. and Sugden, P.H. (1999) Am. J. Cardiol. 83, 64H-69H

8 Bueno, O.F., De Windt, L.J., Tymitz, K.M., Witt, S.A., Kimball, T.R., Klevitsky, R., Hewett, T.E., Jones, S.P., Lefer, D.J., Peng, C.F. et al. (2000) EMBO J. 19, 6341-6350

9 Luo, J., McMullen, J.R., Sobkiw, C.L., Zhang, L., Dorfman, A.L., Sherwood, M.C., Logsdon, M.N., Horner, J.W., DePinho, R.A., Izumo, S. and Cantley, L.C. (2005) Mol. Cell. Biol. 25, 9491-9502

10 Crackower, M.A., Oudit, G.Y., Kozieradzki, I., Sarao, R., Sun, H., Sasaki, T., Hirsch, E., Suzuki, A., Shioi, T., Irie-Sasaki, J. et al. (2002) Cell 110, 737-749

11 Clerk, A., Bogoyevitch, M.A., Anderson, M.B. and Sugden, P.H. (1994) J. Biol. Chem. 269, 32848-32857

12 Braz, J.C., Gregory, K., Pathak, A., Zhao, W., Sahin, B., Klevitsky, R., Kimball, T.F., Lorenz, J.N., Nairn, A.C. and Liggett, S.B. (2004) Nat. Med. 10, 248-254

13 Frey, N., Barrientos, T., Shelton, J.M., Frank, D., Rutten, H., Gehring, D., Kuhn, C., Lutz, M., Rothermel, B., Bassel-Duby, R. et al. (2004) Nat. Med. 10, 1336-1343

14 Fowler, M.R., Naz, J.R., Graham, M.D., Bru-Mercier, G., Harrison, S.M. and Orchard, C.H. (2005) Am. J. Physiol. Heart Circ. Physiol. 288, H2431-H2438

15 Carvalho, B.M., Bassani, R.A., Franchini, K.G. and Bassani, J.W. (2006) Am. J. Physiol. Heart Circ. Physiol. 291, H1803-H1813

16 Sugden, P.H. and Clerk, A. (2005) Curr. Vasc. Pharmacol. 3, 343-351

17 Shubeita, H.E., McDonough, P.M., Harris, A.N., Knowlton, K.U., Glembotski, C.C., Brown, J.H. and Chien, K.R. (1990) J. Biol. Chem. 265, 20555-20562

18 McMullen, J.R., Shioi, T., Huang, W.Y., Zhang, L., Tarnavski, O., Bisping, E., Schinke, M., Kong, S., Sherwood, M.C., Brown, J. et al. (2004) J. Biol. Chem. 279, 4782-4793

19 Sei, C.A., Irons, C.E., Sprenkle, A.B., McDonough, P.M., Brown, J.H. and Glembotski, C.C. (1991) J. Biol. Chem. 266, 15910-15916

20 Schever, J. (1999) Am. J. Cardiol. 83, 70H-74H

21 McDonough, P.M. and Glembotski, C.C. (1992) J. Biol. Chem. 267, 11665-11668

22 Pikkarainen, S., Tokola, H., Kerkela, R., Ilves, M., Makinen, M., Orzechowski, H.D., Paul, M., Vuolteenaho, O. and Ruskoaho, H. (2006) Am. J. Physiol. Regul. Integr. Comp. Physiol. 290, R1639-R1645
23 Molkentin, J.D. (2006) J. Clin. Invest. 116, 623-626

24 Tavi, P., Pikkarainen, S., Ronkainen, J., Niemela, P., Ilves, M., Weckstrom, M., Vuolteenaho, O., Bruton, J., Westerblad, H. and Ruskoaho, H. (2004) J. Physiol. 554, 309-320

25 Mackenzie, L., Bootman, M.D., Laine, M., Berridge, M.J., Thuring, J., Holmes, A., Li, W.H. and Lipp, P. (2002) J. Physiol. 541, 395-409

26 Gruver, C.L., DeMayo, F., Goldstein, M.A. and Means, A.R. (1993) Endocrinology 133, 376-388

27 Song, K., Backs, J., McAnally, J., Qi, X., Gerard, R.D., Richardson, J.A., Hill, J.A., Bassel-Duby, R. and Olson, E.N. (2006) Cell 125, 453-466

28 Molkentin, J.D., Lu, J.R., Antos, C.L., Markham, B., Richardson, J., Robbins, J., Grant, S.R. and Olson, E.N. (1998) Cell 93, 215-228

29 McKinsey, T.A., Zhang, C.L., Lu, J. and Olson, E.N. (2000) Nature 408, 106-111

30 Zhang, C.L., McKinsey, T.A., Chang, S., Antos, C.L., Hill, J.A. and Olson, E.N. (2002) Cell 110, 479-488

31 Li, B., Dedman, J.R. and Kaetzel, M.A. (2006) Biochim. Biophys. Acta 1763, 1275-1281

32 Wu, X., Zhang, T., Bossuyt, J., Li, X., McKinsey, T.A., Dedman, J.R., Olson, E.N., Chen, J., Brown, J.H. and Bers, D.M. (2006) J. Clin. Invest. 116 675-682

33 Vega, R.B., Harrison, B.C., Meadows, E., Roberts, C.R., Papst, P.J., Olson, E.N. and McKinsey, T.A. (2004) Mol. Cell. Biol. 24, 8374-8385

34 Berridge, M.J. (1997) Nature 386, 759-760

35 Dolmetsch, R.E., Lewis, R.S., Goodnow, C.C. and Healy, J.I. (1997) Nature 386, 855-858

36 De Koninck, P. and Schulman, H. (1998) Science 279, 227-230

37 Kuwahara, K., Wang, Y., McAnally, J., Richardson, J.A., Bassel-Duby, R., Hill, J.A. and Olson, E.N. (2006) J. Clin. Invest. 116, 3114-3126

38 Cardenas, C., Liberona, J.L., Molgo, J., Colasante, C., Mignery, G.A. and Jaimovich, E. (2005) J. Cell Sci. 118, 3131-3140

39 Wu, X. and Bers, D.M. (2006) Circ. Res. 99, 283-291

40 Lynch, J., Guo, L., Gelebart, P., Chilibeck, K., Xu, J., Molkentin, J.D. Agellon, L.B. and Michalak, M. (2005) J. Cell Biol. 170, 37-47

41 Kiriazis, H. and Kranias, E.G. (2000) Annu. Rev. Physiol. 62, 321-351

42 Russell, F.D. and Molenaar, P. (2000) Trends Pharmacol. Sci. 21, 353-359

43 Sugden, P.H. (2003) J. Mol. Cell. Cardiol. 35, 871-886

44 Chen, L., Hahn, H., Wu, G., Chen, C.H., Liron, T., Schechtman, D., Cavallaro, G., Banci, L., Guo, Y., Bolli, R. et al. (2001) Proc. Natl. Acad. Sci. U.S.A. 98, 11114-11119

45 Braz, J.C., Bueno, O.F., De Windt, L.J. and Molkentin, J.D. (2002) J. Cell Biol. 156, 905-919

46 Wickenden, A.D., Kaprielian, R., Kassiri, Z., Tsoporis, J.N., Tsushima, R., Fishman, G.I. and Backx, P.H. (1998) Cardiovasc. Res 37, 312-323

47 Kubalova, Z., Terentyev, D., Viatchenko-Karpinski, S., Nishijima, Y., Gyorke, I., Terentyeva, R., da Cunha, D.N., Sridhar, A., Feldman, D.S. Hamlin, R.L. et al. (2005) Proc. Natl. Acad. Sci. U.S.A. 102, 14104-14109

48 Dorn, II, G.W. and Molkentin, J.D. (2004) Circulation 109, 150-158

49 Sipido, K.R., Volders, P.G., Vos, M.A. and Verdonck, F. (2002) Cardiovasc. Res. 53, 782-805

50 Marx, S.O., Reiken, S., Hisamatsu, Y., Jayaraman, T., Burkhoff, D., Rosemblit, N. and Marks, A.R. (2000) Cell 101, 365-376

51 Schmitt, J.P., Kamisago, M., Asahi, M., Li, G.H., Ahmad, F., Mende, U., Kranias, E.G., MacLennan, D.H., Seidman, J.G. and Seidman, C.E. (2003) Science 299, 1410-1413

52 Jones, L.R., Suzuki, Y.J., Wang, W., Kobayashi, Y.M., Ramesh, V., Franzini-Armstrong, C., Cleemann, L. and Morad, M. (1998) J. Clin. Invest. 101, 1385-1393

53 Chu, G., Carr, A.N., Young, K.B., Lester, J.W., Yatani, A., Sanbe, A., Colbert, M.C., Schwartz, S.M., Frank, K.F., Lampe, P.D. et al. (2002) Cardiovasc. Res. 54, 105-116

54 Gomez, A.M., Valdivia, H.H., Cheng, H., Lederer, M.R., Santana, L.F., Cannell, M.B., McCune, S.A., Altschuld, R.A. and Lederer, W.J. (1997) Science 276, 800-806

55 Song, L.S., Sobie, E.A., McCulle, S., Lederer, W.J., Balke, C.W. and Cheng, H. (2006) Proc. Natl. Acad. Sci. U.S.A. 103, 4305-4310

56 Xu, M., Zhou, P., Xu, S.M., Liu, Y., Feng, X., Bai, S.H., Bai, Y., Hao, X.M., Han, Q., Zhang, Y. and Wang, S.Q. (2007) PLoS Biol. 5, e21

57 Aronow, B.J., Toyokawa, T., Canning, A., Haghighi, K., Delling, U., Kranias, E., Molkentin, J.D. and Dorn, II, G.W. (2001) Physiol. Genomics 6, 19-28

Received 18 June 2007

doi:10.1042/BST0350957 